\title{
Heparin therapy in meningococcal septicaemia
}

\author{
JOHN HUNTER \\ From the Children's Hospital, Birmingham
}

\begin{abstract}
Hunter, J. (1973). Archives of Disease in Childhood, 48, 233. Heparin therapy in meningococcal septicaemia. Two cases of meningococcaemia with bad prognostic signs are presented. In one child a state of disseminated intravascular coagulation and defibrinogenation was established. Heparin therapy was used early and successfully in both cases, supporting the value of early anticoagulation in the management of severe meningococcal septicaemia.
\end{abstract}

The mortality remains high in meningococcal septicaemia complicated by the WaterhouseFriderichsen syndrome, despite the apparent improvement in the management of the severely ill child as shown by a review of the experience at the Royal Children's Hospital, Melbourne, over the years 1957 to 1970 (Table I). The role of

TABLE I

Mortality of meningococcaemia at the Royal Children's Hospital, Melbourne, 1957 to 1970

\begin{tabular}{l|c|c|c}
\hline \multicolumn{1}{c|}{ Years } & Cases & Deaths & Mortality (\%) \\
\hline $1957-1959$ & 56 & 7 & 12 \\
$1960-1964$ & 30 & 2 & 7 \\
$1965-1970$ & 27 & 3 & 11 \\
\hline Total & 113 & 12 & 11 \\
\hline
\end{tabular}

disseminated intravascular coagulation in the pathogenesis of this form of irreversible shock has been suggested by a number of factors (Corrigan, Ray, and May, 1968; Hodes, 1969), including the pathological changes seen in fatal cases (Margaretten, Csavossy, and McKay, 1967; Evans et al., 1969; Fox, 1971). Laboratory evidence of intravascular coagulation and defibrinogenation has been found in fatal cases of meningococcal septicaenia (McGehee, Rapaport, and Hjort, 1967). In view of this association, heparin therapy has been used but results have been disappointing (Hitzig, 1964; Najjar and Ahmad, 1969). The failure has been attributed by some to delay in the initiation of heparin therapy. To overcome this delay we have attempted to use a combination of readily available prognostic features which may predict those

Received 20 July 1972. patients with a poor prognosis (Stiehm and Damrosch, 1966). Using these criteria we have been able to identify 2 patients with poor prognostic scores, in 1 of whom evidence of disseminated intravascular coagulation was established. In both patients a satisfactory outcome was associated with early heparin treatment.

\section{Case histories}

Case 1. This 26-month-old boy was admitted with a 10-hour history of abdominal pain, vomiting, and fever, having had no previous significant illness. On admission he was stuporose, with a blood pressure of $95 \mathrm{mmHg}$ systolic, but was not in peripheral circulatory failure. There were a few scattered petechiae about the mouth and on the buttock. Within 1 hour of admission his condition deteriorated with the development of periphery circulatory failure and further petechiae on the chest and abdomen. Resuscitation was started with intravenous plasma albumin, sodium bicarbonate, and hydrocortisone $(45 \mathrm{mg} / \mathrm{kg})$. On the basis of the unfavourable prognostic features, a heparin infusion was started with an immediate dose of 150 units $/ \mathrm{kg}$ followed by 200 units $/ \mathrm{kg}$ 6-hourly by constant rate infusion. Penicillin, methicillin, and chloramphenicol were administered intravenously and the child was digitalized and placed in oxygen.

Investigations showed a Neisseria meningitidis group $\mathrm{C}$ in the blood culture; normal CSF; normal serum electrolytes with a metabolic acidosis; $\mathrm{Hb} 13 \cdot 1 \mathrm{~g} / 100$ $\mathrm{ml}$, white cell count $3900 / \mathrm{mm}^{3}$, platelets $150,000 / \mathrm{mm}^{3}$. Coagulation studies before starting heparin showed a partial thromboplastin time of 123 minutes (control 49 minutes), prothrombin time of 22 minutes (control 14 minutes), fibrinogen $103 \mathrm{mg} / 100 \mathrm{ml}$ (normal 200 to $400 \mathrm{mg} / 100 \mathrm{ml}$ ), serum fibrin degradation products $1 / 2048$ (normal 0 to $1 / 16$ ), plasminogen 0.8 units.

These results confirmed the presence of intravascular coagulation, and heparin therapy was maintained for 72 hours, during which time he was given $500 \mathrm{ml}$ whole fresh blood because of a progressive anaemia. 3 hours 
after onset of therapy the child appeared to have recovered from the shock state with an improving peripheral circulation, a blood pressure of $125 \mathrm{mmHg}$ systolic, and a central venous pressure steady at $13 \mathrm{~cm}$ $\mathrm{H}_{2} \mathrm{O}$.

The subsequent course was uneventful. After heparinization for 48 hours, the fibrin degradation products had fallen to $1 / 16$, within normal limits. Despite the adequate heparinization, there was a progressive thrombocytopenia over the first 4 days with daily platelet counts of $150,000,24,000,8000,16,000$, $183,000 / \mathrm{mm}^{3}$. No extension of the petechiae was observed after heparinization. Penicillin was continued for 7 days, other antibiotics being discontinued because of the blood culture result; digoxin was discontinued after the initial dose, and the hydrocortisone was gradually reduced over the subsequent week. The child subsequently required skin grafting to a small area of skin necrosis over the heel and calf.

Case 2. This 3-year-old boy presented with an 8hour history of fever, confusion, and ataxia. On admission he was restless and disorientated with peripheral circulatory failure and hypotension (BP $80 \mathrm{mmHg}$ systolic). A scattered petechial rash was noted on the trunk and thighs. Resuscitation was undertaken with plasma, sodium bicarbonate, and hydrocortisone (35 $\mathrm{mg} / \mathrm{kg}$ ). In view of the prognosis, a heparin infusion was started. Blood culture grew a Neisseria meningitidis that was also isolated from the CSF, which was otherwise normal. The serum electrolytes were normal with a metabolic acidosis. $\mathrm{Hb} 12 \cdot 3 \mathrm{~g} / 100 \mathrm{ml}$, white cell count $4000 / \mathrm{mm}^{3}$, platelet count $230,000 / \mathrm{mm}^{3}$. Coagulation studies were not available. He was treated with penicillin, chloramphenicol, and sulphadimidine initially, penicillin being continued for 7 days, and the other antibiotics discontinued after the results of the cultures were known. After some initial worsening of his general condition over the first 2 hours, the child showed an improvement in peripheral circulation and conscious state. 10 hours after starting treatment for shock, he had a further hypotensive collapse which responded to $100 \mathrm{mg}$ i.v. hydrocortisone. Subsequent to this episode the child made a steady improvement, though remaining slightly hypotensive for 36 hours. Heparinization was undertaken on admission with an immediate dose of 150 units $/ \mathrm{kg}$ and maintained at 100 units/kg 6-hourly by infusion. Anticoagulation was maintained for 48 hours, and during this time he was transfused with $500 \mathrm{ml}$ fresh whole blood because of increasing anaemia. There was a progressive thrombocytopenia over the first 4 days (daily platelet counts of $\left.230,000,120,000,66,000,42,000,100,000 / \mathrm{mm}^{3}\right)$, but no other evidence of intravascular coagulation. The skin lesions showed no extension after heparinization. His subsequent course was uneventful and steroids were discontinued after 8 days.

\section{Discussion}

Both cases of meningococcal septicaemia described here had a poor prognosis in terms of the
TABLE II

Unfavourable prognostic features in meningococcal septicaemia (after Stiehm and Damrosch, 1966)

Petechiae $<12$ hours before admission

Presence of shock

Absence of meningitis ( $<20$ white blood cells $/ \mathrm{mm}^{3}$ in CSF)

Blood leucocyte count $<10,000$ white blood cells $/ \mathrm{mm}^{3}$

Erythrocyte sedimentation rate $<10 \mathrm{~mm} / \mathrm{hr}$

factors listed by Stiehm and Damrosch (1966) (Table II). The normal ESR may relate to a lowered serum fibrinogen. A review of 113 cases of bacteriologically proven cases of meningococcaemia at the Royal Children's Hospital, Melbourne, from 1957 to 1970, confirmed the prognostic value of these criteria, such that those cases with more than 3 of these features present were associated with a very high mortality (Table III). Other factors, including age, sex, thrombo-

TABLE III

Mortality of meningococcaemia admitted to the Royal Children's Hospital, Melbourne, 1957 to 1970

\begin{tabular}{|c|c|c|c|}
\hline \multicolumn{4}{|c|}{ Mortality related to prognostic score (Table II) } \\
\hline $\begin{array}{l}\text { Prognostic } \\
\text { score }\end{array}$ & Cases & Deaths & $\begin{array}{c}\text { Mortality } \\
(\%)\end{array}$ \\
\hline $\begin{array}{l}0 \\
1 \\
2 \\
3 \\
4\end{array}$ & $\begin{array}{r}15 \\
50 \\
30 \\
16 \\
2\end{array}$ & $\begin{array}{l}0 \\
0 \\
1 \\
9 \\
2\end{array}$ & $\begin{array}{r}0 \\
0 \\
3 \\
56 \\
100\end{array}$ \\
\hline
\end{tabular}

cytopenia, or lack of the normal eosinopenic response to infection (Hodes, Moloshok, and Markowitz, 1952), were not found to be significant in assessing prognosis. Hypokalaemia was noted at some stage in the illness of several of the fatal cases (Mauger, 1971); however, this was also observed in a number of cases with successful outcome. The use of the prognostic score was found to be more accurate than the clinical impression of the attending physician in predicting the outcome. The role of intravascular coagulation in those patients with a poor prognosis has been inferred by the study of McGehee et al. (1967) who described 19 patients with meningococcal septicaemia, 5 of whom had proven intravascular coagulation and a universally fatal outcome: in the remaining cases without evidence of intravascular coagulation only 1 death occurred. Pathological studies have further suggested the importance of intravascular coagulation in the fatal cases of meningococcal septicaemia (Margaretten et al., 1967; 
Evans et al., 1969; Fox, 1971). A case of meningococcaemia has recently been described with proven disseminated intravascular coagulation successfully treated with heparin despite the delay inevitable when evidence of intravascular coagulation is sought before heparinization (Willoughby, McMorris, and Goel, 1972).

The use of the platelet count, prothrombin time, and partial thromboplastin time to screen rapidly for the presence of intravascular coagulation has been suggested (Winkelstein et al., 1969). Corrigan et al. (1968) found these tests to be abnormal in $24 \%$ of septicaemic patients without intravascular coagulation and recommended the use of the platelet count, factor $\mathrm{V}$ assay, and the presence of fibrin split products for the diagnosis of this state. The thrombocytopenia seen in Case 1 occurred in the presence of normal fibrin split products suggesting a cause other than intravascular coagulation.

The Stiehm and Damrosch prognostic score may be used, as in the present cases, to overcome the delay in heparinization imposed by the need for laboratory diagnosis of intravascular coagulation. The factors involved in the prognostic score are readily available and enable the delineation of a group of patients at risk. Interim heparinization can be begun while awaiting the laboratory confirmation of intravascular coagulation and defibrinization. This also limits the use of heparin in patients in whom the risk of intravascular coagulation is slight.

I thank Drs. L. E. G. Sloan and D. McCreadie of the Royal Children's Hospital, Melbourne, and R. H. R. White of Birmingham Children's Hospital, for permis- sion to publish their cases; the physicians of the Royal Children's Hospital, for the opportunity to review their experience; and Dr. A. S. McNeish, for his help in the preparation of the manuscript.

\section{REFERENCES}

Corrigan, J. J., Ray, W. L., and May, N. (1968). Changes in the blood coagulation system associated with septicemia. New England fournal of Medicine, 279, 851.

Evans, R. W., Glick, B., Kimball, F., and Lobell, M. (1969). Fatal intravascular consumption coagulopathy in meningococcal sepsis. American fournal of Medicine, 46, 910.

Fox, B. (1971). Disseminated intravascular coagulation and the Waterhouse-Friderichsen Syndrome. Archives of Disease in Childhood, 46, 680.

Hitzig, W. H. (1964). Therapie mit antikoagulantien in der pädiatrie. Helvetica Paediatrica Acta, 19, 213.

Hodes, H. L. (1969). Care of the critically ill child: endotoxin shock. Pediatrics, 44, 248.

Hodes, H. L., Moloshok, R. E., and Markowitz, M. (1952). Fulminating meningococcemia treated with cortisone; use of blood eosinophil count as a guide to prognosis and treatment. Pediatrics, 10, 138.

McGehee, W. G., Rapaport, S. I., and Hjort, P. F. (1967). Intravascular coagulation in fulminant meningococcemia. Annals of Internal Medicine, 67, 250.

Margaretten, W., Csavossy, I., and McKay, D. G. (1967). An electron microscope study of a case of meningococcemia in man. American fournal of Diseases of Children, 114, 268.

Mauger, D. C. (1971). Hypokalaemia as a constant feature of fulminant meningococcal septicaemia. Australian Paediatric fournal, 7, 84.

Naijar, S. S., and Ahmad, M. (1969). Heparin therapy in fulminant meningoccemia. Fournal of Pediatrics, 75, 449.

Stiehm, E. R., and Damrosch, D. S. (1966). Factors in the prognosis of meningoccal infection. Fournal of Pediatrics, 68, 457.

Willoughby, M. L. N., McMorris, S., and Goel, K. M. (1972) Disseminated intravascular coagulation in meningococcal infection. Archives of Disease in Childhood, 47, 324.

Winkelstein, A. Songster, C. L., Caras, T. S., Berman, H. H., and West, W. L. (1969). Fulminant meningococcemia and disseminated intravascular coagulation. Archives of Internal Medicine, 124, 55.

Correspondence to Dr. John Hunter, Children's Hospital, Ladywood Middleway, Birmingham. 